\title{
Gas-loading furnace for deuterium-charged alloy-casting
}

Cite as: Rev. Sci. Instrum. 91, 043901 (2020); https://doi.org/10.1063/5.0004356

Submitted: 10 February 2020 . Accepted: 30 March 2020 . Published Online: 20 April 2020

T. Werner, P. Lehmann, J. Baumann, (D) F. Kargl, and B. Tyburska-Püschel
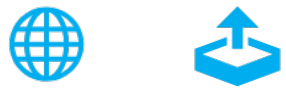

\section{ARTICLES YOU MAY BE INTERESTED IN}

A novel instrument for investigating the dynamic microstructure evolution of high temperature service materials up to $1150^{\circ} \mathrm{C}$ in scanning electron microscope

Review of Scientific Instruments 91, 043704 (2020); https://doi.org/10.1063/1.5142807

A compact high-resolution spectrometer based on a segmented conical crystal analyzer Review of Scientific Instruments 91, 043105 (2020); https://doi.org/10.1063/1.5141758

Boron-MgO composite as an X-ray transparent pressure medium in the multi-anvil apparatus

Review of Scientific Instruments 91, 043903 (2020); https://doi.org/10.1063/1.5137740

What are your needs for periodic signal detection?

\section{Challenge us.}

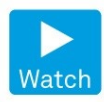

Zurich

Instruments

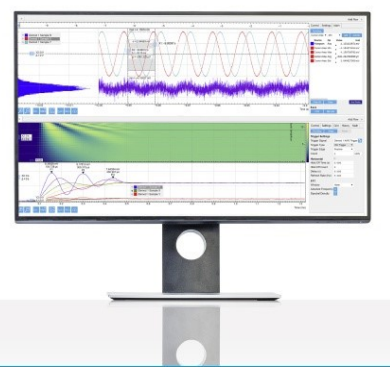

Rev. Sci. Instrum. 91, 043901 (2020); https://doi.org/10.1063/5.0004356 91, 043901 


\title{
Gas-loading furnace for deuterium-charged alloy-casting
}

\author{
Cite as: Rev. Sci. Instrum. 91, 043901 (2020); doi: 10.1063/5.0004356 \\ Submitted: 10 February 2020 - Accepted: 30 March 2020 • \\ Published Online: 20 April 2020
}

T. Werner, P. Lehmann, J. Baumann, F. Kargl, ${ }^{\text {a) }}$ (D) and B. Tyburska-Püschel

AFFILIATIONS
Institut für Materialphysik im Weltraum, Deutsches Zentrum für Luft- und Raumfahrt (DLR), 51147 Köln, Germany

a) Author to whom correspondence should be addressed: Florian.Kargl@dlr.de

\begin{abstract}
A furnace was developed and characterized to allow for safe and controlled gas-loading or degassing of alloys. This oven is able to process samples under varying atmospheres, such as high vacuum or nitrogen containing $10 \mathrm{vol}$ \% deuterium, as well as for pressures up to 800 $\mathrm{hPa}$. Thermal desorption spectroscopy and scanning electron microscopy demonstrate the enhancing effects of high loading-gas concentration, high pressures, high temperatures above liquidus (50-150 K above the liquidus temperature of the cast hypoeutectic aluminum-copper model-alloy), and long holding times (up to $60 \mathrm{~min}$ ) on the amount of retained gas in the solidified sample. Lack of copper segregation in the casting is confirmed by energy dispersive $\mathrm{x}$-ray diffraction and Rutherford backscattering spectroscopy. It is shown that the facility allows for the controlled generation of distinct amounts of gas pores, down to a nil amount (only shrinkage porosity appearing in the sample).
\end{abstract}

Published under license by AIP Publishing. https://doi.org/10.1063/5.0004356

\section{INTRODUCTION}

In recent years, the interest of the materials science community has increasingly been drawn to the topic of microporosity in metallic materials. ${ }^{1-5}$ These microscopic defects are known to severely impact the mechanical properties of cast alloys, and, thus, the understanding of the factors influencing the pore's formation and growth is of great importance to the casting industry. ${ }^{6-8}$ The micropores are the result of three main mechanisms: Formation of bifilms, shrinkage, and decrease in gas solubility upon solidification. Those effects usually take place simultaneously and are highly dependent on environmental factors and the casting setup, notably atmosphere composition, air humidity, and temperature. In order to observe shrinkage and gas pores separately, precise control over the amount of gas dissolved in the melt is needed: if upon solidifying, the alloy becomes supersaturated with gas, mostly gas bubbles will form, and if the gas concentration is subcritical, however, there will be only shrinkage without gas porosity. Gas porosity can be observed throughout almost the entire solidification process, starting from the formation of round bubbles in the melt, whereas shrinkage porosity will form at the end of solidification. ${ }^{2,8,9} \mathrm{Up}$ until now, research on the topic mostly achieved gas-loading through passive methods, such as casting the metallic alloys under atmospheric conditions, then correlating the daily air humidity with the resulting porosity, ${ }^{2}$ or by introducing effervescent tablets into the hot melt. ${ }^{10}$ However, these approaches do not allow for accurate control over gas saturation. Thus, the need arises for a casting furnace enabling calibrated adjustment of all environmental factors so as to eliminate or promote the desired type of porosity. To fulfill those needs, HEPHAESTUS (Hydrogen-Equilibrium-Pressure loading-furnace for Homogenous Alloying of Elemental metals and Smelting or Tempering of Unoxidized Samples) was designed, allowing a clean and safe casting environment, with the option of die-casting under different atmospheres, notably under deuterium (D). The use of D instead of hydrogen $(\mathrm{H})$ allows the differentiation via thermal desorption spectroscopy (TDS) between actively added D and $\mathrm{H}$ that did not degas or enter the sample later on through diffusion.

\section{FURNACE DESIGN}

The main component of the oven (Fig. 1) consists of a tempered alumina silicate (Rescor 902) crucible from Cotronics Corp., which sustains working temperatures up to $1400 \mathrm{~K}$. The heat input is realized via a molybdenum heater inlaid in a concentric spiral-channel 


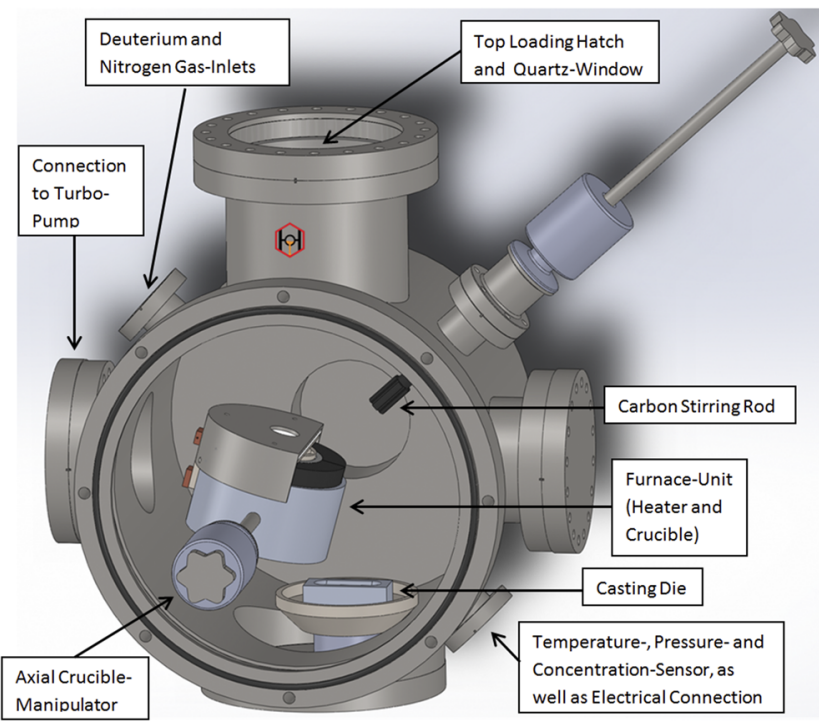

FIG. 1. 3D model of the gas-loading furnace HEPHAESTUS with the front plate removed. Material is loaded and the cooled-down casting is removed through the top hatch. Clockwise rotation of the axial crucible manipulator allows pouring of the melt into the casting mold below. The casting die sits on an $\mathrm{Al}_{2} \mathrm{O}_{3}$ overflow protection plate. To insert the carbon stirring rod, the furnace unit is rotated by $45^{\circ}$ clockwise so as to align the opening in the steel cover with the stirring rod.

on the outer wall of the cylindrical crucible. $\mathrm{Al}_{2} \mathrm{O}_{3}$ (aluminum oxide) felt insulation [ZIRCAR Ceramics Alumina Paper Type APA, thermal conductivity at $773 \mathrm{~K}: 0.09 \mathrm{~W}(\mathrm{~K} \mathrm{~m})^{-1}$ ] surrounded by carbon-foam (Schunk Kohlenstofftechnik GmbH Kohlenstoffschaum FU4640, thermal conductivity at $773 \mathrm{~K}: 0.21 \mathrm{~W}(\mathrm{~K} \mathrm{~m})^{-1}$ ) and a steel-cover ensure maximal heat input into the crucible while minimizing external heat losses. The crucible can be rotated manually around the horizontal axis by a manipulator accessible from outside the chamber. Stirring of the melt is achieved through the use of a $\varnothing 15 \mathrm{~mm}$ carbon mixing-rod operated in the same manner. The casting-setup has been contained inside a $24200 \mathrm{~cm}^{3}$ stainless-steel high-vacuum chamber (reaching pressures below $5 \times 10^{-4} \mathrm{hPa}$ in $10 \mathrm{~min}$ ) for degassing of the melt. A prevacuum of $10^{-1} \mathrm{hPa}$ is drawn by a Pfeiffer Adixen ACP28 prepump. Once the maximum vacuum is reached by using a Pfeiffer Vacuum HiPace 300 turbo pump with a TC 400 Controller, two separate gas inlets allow for different casting atmospheres. For the subsequent experiments, the chosen gases were nitrogen $(\mathrm{N})$ of $99.99 \%$ purity and a N-10 vol. \% D mix, both provided by Linde AG.

To ensure a safe smelting environment while introducing a highly explosive gas, the furnace exhibits a certain number of features designed to allow control of the gas concentration and the pressure and temperature. These three factors are critical in determining the flammability of the gas mix: the lower detonation limit (LDL) is determined by the minimum concentration-ratios capable of detonation, while the upper detonation limit (UDL) scales with the maximum concentration-ratios still capable of detonation. Lower pressures and higher temperatures marginally increase the detonation range. On the other hand, the addition of $\mathrm{N}$ reduces the UDL and increases the LDL, as it delays ignition and reduces the speed of flame propagation. In the present setup, in the case of critical failure, the maximum concentration of $\mathrm{D}$, notably $10 \mathrm{vol}$. \%, will still fall short of the LDL of 19 vol. $\%{ }^{11-13}$ Typical working conditions entail temperatures up to $1073 \mathrm{~K}$, gas concentrations of up to $10 \mathrm{vol}$. \% D in $\mathrm{N}$-atmosphere, and pressures of $50 \mathrm{hPa}, 200 \mathrm{hPa}, 500 \mathrm{hPa}$, and 800 $\mathrm{hPa}$. In this setup, $\mathrm{N}$ will act as a sufficient $\mathrm{H}$-combustion inhibitor in the case of critical failure of the facility according to current NASA safety standards. ${ }^{11}$

The alloyed metals are aluminum (Al) $99.99 \%$ purity and 99.95\% purity copper $(\mathrm{Cu})$ both from Alfa Aesar and are cast into a stainless steel die featuring a free cooling rate of up to $25.3 \mathrm{~K}$ $\mathrm{s}^{-1}$ in the temperature regime of hypoeutectic $\mathrm{Al}-\mathrm{Cu}$ solidification (see Sec. III B 1). As $\mathrm{H}$ and its isotopes are the only gases solved in relevant amounts in $\mathrm{Al}^{2}$ the $\mathrm{Al}-\mathrm{Cu}$ system was chosen as the model alloy for simplicity. The maximum casting-volume amounts to $14 \mathrm{~cm}^{3}$. The produced samples have a $50 \mathrm{~mm}$ long and $12 \mathrm{~mm}$ wide obround cross section with a height of $30 \mathrm{~mm}$. Preliminary tests showed that dies with obround cross section, when compared to those with a rectangular cross section, reduce gas entrapment close to the die walls during the pouring of the melt, in agreement with the literature. ${ }^{14}$ The whole metallurgical process can be visually followed through a quartz-glass window inserted into the loading hatch on the upper face of the facility. Temperature is monitored via a K-type thermocouple ( $1 \mathrm{~mm}$ diameter) encased in an $\mathrm{Al}_{2} \mathrm{O}_{3}$ tube (an outer diameter of $2 \mathrm{~mm}$ ) and attached to the inner crucible wall using Ceramabond 670 high-temperature $\mathrm{Al}_{2} \mathrm{O}_{3}$ adhesive by Aremco. The power-output of an Elektro-Automatik EAPSI 5040-40A power supply unit is adjusted by using a Eurotherm 3216 temperature/process controller according to the voltage supplied by that thermocouple. The temperature collection unit (controller and thermocouple) was calibrated using a Sika Temperature Calibrator Type TP 281300E, in combination with a reference thermocouple certified by the German calibration service (Deutscher Kalibierdienst DKD). Pressure and gas concentration are captured by using a Pirani sensor (Pfeiffer Vacuum, TPR 281) and a custom calibrated D-sensor (Stange, Type SE-H2-S-AZ), respectively.

\section{FURNACE PERFORMANCE}

\section{A. Methods}

\section{Casting under different atmospheres}

The different samples, smelted while varying individual process parameters, each contains distinct amounts of dissolved gas. Upon pouring the liquid metal, diffusion out of the melt is limited by the high cooling rates. Thus, the solid metal matrix becomes supersaturated in gas and/or gas pores are formed. ${ }^{8}$ In the presented setup, under high vacuum $\left(5 \times 10^{-4} \mathrm{hPa}\right), \mathrm{Al}$ and $\mathrm{Cu}$ bits in a weight-ratio of 90:10 and with a total weight of $40 \mathrm{~g}$ are first degassed, minimizing the amount of dissolved $\mathrm{H}$. A primary heating step increases the temperature to $775 \mathrm{~K}$ ( $50 \mathrm{~K}$ below the $\alpha-\theta$ eutectic temperature of $\mathrm{Al}-\mathrm{Cu}$ ). Following a $30 \mathrm{~min}$ long holding time of the solid raw materials at $775 \mathrm{~K}$, an increase in the heat input to the end temperature $(50 \mathrm{~K}, 100 \mathrm{~K}$, or $150 \mathrm{~K}$ above liquidus) results in the sample melting in the process. Subsequently, the $\mathrm{N}-10$ vol. \% D mix is introduced until the selected end-pressure is reached. After a set holding time, the D-loaded alloy is cast into 


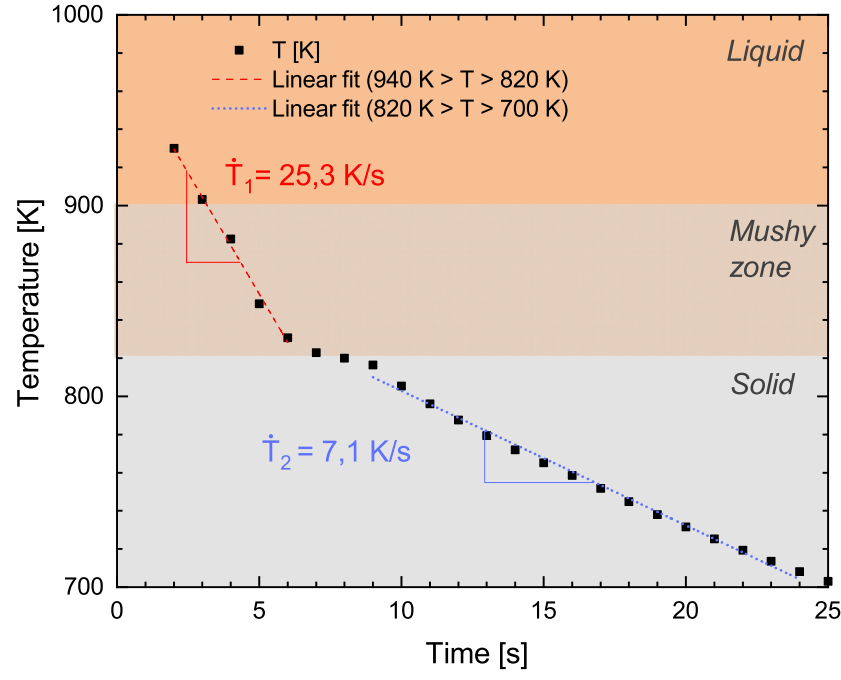

FIG. 2. Temperature profile captured during the casting and solidification process of an $\mathrm{Al}-10 \mathrm{wt}$ \% $\mathrm{Cu}$ alloy. In the crystallization range of the alloy, two linearly averaged cooling rates $\dot{\mathrm{T}}_{1}=25.3 \mathrm{Ks}^{-1}$ (red) and $\dot{\mathrm{T}}_{2}=7.1 \mathrm{Ks}^{-1}$ (blue) were determined when casting in a stainless steel die. Sufficient linearity is assumed based on the short time intervals of $5 \mathrm{~s}$ and $15 \mathrm{~s}$ when compared to the total cooldown time of $1800 \mathrm{~s}$. The eutectic phase-transformation plateau caused by the latent heat excess results in a discontinuity of the cooling rate close to $820 \mathrm{~K}$. Conversely, the solid-liquid plateau appears negligible considering the accuracy of this measurement. The transition between $\dot{\mathrm{T}}_{1}$ and $\dot{\mathrm{T}}_{2}$ is attributed to the difference in thermal conductivity of the liquid melt/mushy zone and the solid alloy after complete crystallization.

a stainless steel die where it solidifies within $10 \mathrm{~s}$, as seen in Fig. 2. An Al-10 wt. \% Cu sample cast under a N-10 vol. \% D atmosphere of $500 \mathrm{hPa}$, with a holding time of $60 \mathrm{~min}$ and a temperature above liquidus (T.a.L., or superheating) of $150 \mathrm{~K}$, serves as a reference sample. For the other castings, only a single parameter is varied in each measurement, see Table I:
- The pressure $\mathrm{p}$ inside the casting chamber $(50 \mathrm{hPa}, 200 \mathrm{hPa}$, $500 \mathrm{hPa}$, and $800 \mathrm{hPa}$ ). As the setup is designed as a vacuum chamber, only pressures below $1000 \mathrm{hPa}$ have been realized.

- The holding time $t$ of the molten sample under D atmosphere (15 min, $30 \mathrm{~min}$, and $60 \mathrm{~min}$ ).

- The temperature above liquidus T (50 K, $100 \mathrm{~K}$, and $150 \mathrm{~K}$ ) at which the melt is held for the time $t$.

- The $\mathrm{D}$ concentration of the N-D atmosphere inside the pressure chamber (2 vol. \% D, 5 vol. \% D, and 10 vol. \% D).

\section{Cooling rate measurements}

A $0.5 \mathrm{~mm}$ diameter K-type thermocouple, fixed to the inner wall of the casting die with a thin layer of $\mathrm{Al}_{2} \mathrm{O}_{3}$ adhesive, captures the solidifying alloy's temperature. The data are collected at a frequency of $1 \mathrm{~Hz}$ with a Keysight Technologies 34970A data acquisition unit.

\section{Sample preparation}

Secondary Electron Microscopy (SEM) requires flat sample surfaces. The samples to be analyzed are cut at set distances $(5 \mathrm{~mm}$, $10 \mathrm{~mm}$, and $15 \mathrm{~mm}$ ) from the bottom face and ground according to the ASTM standard E3-11 ${ }^{15}$ to a thickness of $250 \mu \mathrm{m}$. The cutting is performed at $1700 \mathrm{rpm}$ and a feed-rate of $1.2 \mathrm{~mm} \mathrm{~min}^{-1}$ on a Buehler Isomet 4000 Linear Precision Saw equipped with a Buehler MetAbrase abrasive cutoff wheel. Afterward, the cut pieces are successively ground on p800, p1200, p2500, and p4000 grit Buehler CarbiMet $\mathrm{SiC}$ abrasive paper lubricated with water at $200 \mathrm{rpm}$ for $2 \mathrm{~min}$, $5 \mathrm{~min}, 10 \mathrm{~min}$, and $15 \mathrm{~min}$, respectively. Eventually, the samples are cleaned in an ultrasound bath with isopropanol for $3 \mathrm{~min}$.

\section{Secondary electron microscopy and energy dispersive $x$-ray spectroscopy}

Surface topography and chemical composition are analyzed by SEM and energy-dispersive $\mathrm{x}$-ray spectroscopy (EDX). The basic principles of SEM and EDX are explained in Ref. 16. The hardware consists of a Zeiss Merlin Gemini SEM with a Schottky-type emitter combined with an Oxford Instruments X-Max ${ }^{\mathrm{N}} 50$ Silicon

TABLE I. List of cast samples and the corresponding casting parameters (varied parameters for each set highlighted in bold).

\begin{tabular}{|c|c|c|c|c|c|c|}
\hline Cast sample & Series & $\begin{array}{c}\text { Al-xCu } \\
\text { (wt. \%) }\end{array}$ & $\begin{array}{l}\mathrm{T}_{\text {cast }} \\
(\mathrm{K})\end{array}$ & $\mathrm{t}(\min )$ & $\mathrm{p}(\mathrm{hPa})$ & $c(D)($ vol. \%) \\
\hline Al10Cu T150t60p500D10 & Reference sample & 10 & 1057 & 60 & 500 & 10 \\
\hline Al10Cu T100t60p500D10 & Variation of overheating & 10 & 1007 & 60 & 500 & 10 \\
\hline Al10Cu T50t60p500D10 & Variation of overheating & 10 & 957 & 60 & 500 & 10 \\
\hline Al10Cu T150t30p500D10 & Variation of holding time & 10 & 1057 & 30 & 500 & 10 \\
\hline Al10Cu T150t15p500D10 & Variation of holding time & 10 & 1057 & 15 & 500 & 10 \\
\hline Al10Cu T150t60p800D10 & Variation of pressure & 10 & 1057 & 60 & 800 & 10 \\
\hline Al10Cu T150t60p200D10 & Variation of pressure & 10 & 1057 & 60 & 200 & 10 \\
\hline Al10Cu T150t60p50D10 & Variation of pressure & 10 & 1057 & 60 & 50 & 10 \\
\hline Al10Cu T150t60p500D5 & Variation of D-concentration & 10 & 1057 & 60 & 500 & 5 \\
\hline Al10Cu T150t60p500D2 & Variation of D-concentration & 10 & 1057 & 60 & 500 & 2 \\
\hline
\end{tabular}


Drift Detector (EDX Detector). The analysis of the characteristic Kand L-lines was performed according to ASTM Standard E150812a for quantitative analysis by energy-dispersive spectroscopy ${ }^{17}$ on Oxford Instrument's Aztec 3.3 software, yielding stoichiometric results. Working distance and acceleration voltage were kept constant for all measurements at $15 \mathrm{~mm}$ and $20 \mathrm{kV}$, respectively, with a takeoff angle of $35^{\circ}$, as well as a magnification of $100 \times$. Images were taken by using a back-scattered electron (BSE) detector, with the maximum area of analysis amounting to $5.3 \mathrm{~mm}^{2}$. This also corresponds to the area of analysis of the EDX scan averaging the elemental distribution over this area (Aztec 3.3 "Analysis" mode) with a depth of $2 \mu \mathrm{m}$ and a fractional sensitivity detection limit of 0.1 wt. \%. ${ }^{16}$ Error bars for EDX are mainly influenced by the standard deviation of the chemical composition of all measured areas on a sample. The matrix correction-function implemented in the software is the eXtended Pouchou and Pichoir (XPP) method, a modified version of the commonly used Phi-Rho- $Z$ approach. ${ }^{18}$ Calibration of the EDX sensor was performed on a cobalt sample.

\section{Rutherford backscattering spectrometry}

While EDX covers a broader area of the sample, Rutherford Backscattering Spectrometry (RBS) analysis yields the elemental composition of the $\varnothing 1 \mathrm{~mm}$ beam-spot not only to greater depth but also with high depth-resolution. The depth of analysis calculated by using the data processing software SIMNRA 7.02 exceeds $8 \mu \mathrm{m}$ with a depth-resolution of $25 \mathrm{~nm} .{ }^{19}$ This software was also used for the RBS analysis. RBS, while more time and cost intensive, allows for a more precise elemental analysis of the samples than EDX. Furthermore, it is an indirect and non-destructive method for elemental depth-profiling. A more detailed description of the RBS technique can be found in Ref. 20. The RBS measurements were performed at the Max Planck Institute for Plasma Physics in Garching, Germany, using the $3 \mathrm{MV}$ Tandem ion accelerator (from High Voltage Engineering Europa B.V.). The $2.5 \mathrm{MeV}^{4} \mathrm{He}^{+}$ion beam, perpendicular to the sample surface, was back-scattered onto a silicon solid state detector (solid angle $1.108 \pm 0.038 \mathrm{msr}$ ) placed at an angle of $165^{\circ}$, yielding an accumulated charge of $5 \mu \mathrm{C}$. The employed ion beam had a diameter of $1 \mathrm{~mm}$. Given these parameters, the detection limit as calculated by SIMNRA 7.02 amounted to 1 at. \% for both $\mathrm{Al}$ and Cu. ${ }^{19}$ For RBS, the error bar was mainly governed by the Poisson noise. The inaccuracy of the Rutherford cross section, current measurements, and scattering, as well as solid angles, contributes about $1 \%$ to the error bar.

\section{Thermal desorption spectroscopy}

TDS is used for quantification of retained gas: after heating up a $0.5 \mathrm{~g}$ specimen of each casting to $925 \mathrm{~K}$, a Pfeiffer Vacuum Prisma 200 quadrupole mass spectrometer ionizes the outgassing elements and detects the resulting ion flow. The data output is further processed with Balzer Quadstar software using the internal multiple ion detection (MID) settings. For each sample, 500 MID cycles are run over the period of two hours. The accuracy of the measurements is ensured by cross-comparison with a second TDS setup at the Institute of Energy and Climate Research in Jülich, Germany. The absolute sensitivities were determined using calibrated bottle leaks of $\mathrm{H}_{2}$ and $\mathrm{D}_{2}$, yielding an error bar of $10 \%$. Given the TDS method's resolution of single atomic mass units (amu), retained D atoms can be differentiated from trapped $\mathrm{H}$ atoms. For more information on the principles of TDS, see Ref. 21. In the presented experiment, each sample was checked for traces of dihydrogen (2 amu), water (18 amu), ammonia (17 amu), and methane (16 amu) as the most common outgassing molecules for $\mathrm{Al}-\mathrm{Cu}$ alloys according to a preliminary calibration experiment. Special focus was put on the compounds that had one or more $\mathrm{D}$ atoms substituted, notably $\mathrm{DH}$, $\mathrm{D}_{2}, \mathrm{HDO}, \mathrm{D}_{2} \mathrm{O}, \mathrm{NH}_{2} \mathrm{D}, \mathrm{NHD}_{2}, \mathrm{ND}_{3}, \mathrm{CH}_{3} \mathrm{D}, \mathrm{CH}_{2} \mathrm{D}_{2}, \mathrm{CHD}_{3}$, and $\mathrm{CD}_{4}$. However, as only $\mathrm{DH}$ and $\mathrm{D}_{2}$ showed significant differences compared with the D-free samples, the focus of the ensuing analysis was on these two molecules. Eventually, the total number of $\mathrm{D}$ atoms was determined by the addition of a doubled $\mathrm{D}_{2}$ signal to the $\mathrm{DH}$ signal. The subsequent analysis gives an account on how changing the casting parameters will affect the quantity of retained D atoms. Due to the melting of the specimen for the evaluation, TDS is a destructive method of analysis, thus corresponding to the last step of the experimental process in the present work.

\section{B. Results}

\section{Free cooling rate}

In the temperature range of $940-700 \mathrm{~K}$ (a temperature above the melting point of pure $\mathrm{Al}$ and a temperature below the $\alpha-\theta$ eutectic temperature, ${ }^{2}$ respectively) the furnace offers a cooling rate of $25.3 \mathrm{~K} \mathrm{~s}^{-1}$ for liquid metal and $7.1 \mathrm{~K} \mathrm{~s}^{-1}$ for the solidified alloy (see Fig. 2). Cooldown to $370 \mathrm{~K}$ is reached after $30 \mathrm{~min}$. It should be noted that a temperature-controlled cooldown is impossible in this setup, as solidification occurs upon pouring the liquid metal into the

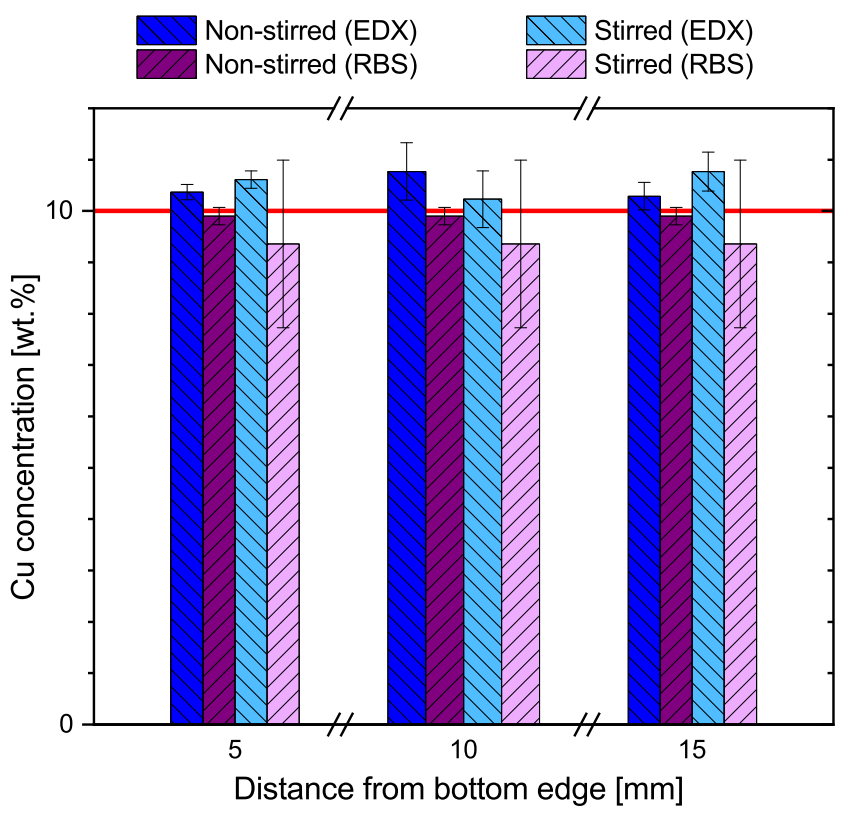

FIG. 3. Slices cut from the castings at different heights show segregating $\mathrm{Cu}$ (the heavier element in the Al-Cu alloy) neither for stirred (light blue, light purple) nor for non-stirred (dark blue, dark purple) samples. Both RBS (light and dark purple) and EDX (light and dark blue) results are consistent within the error bars. Considering the smaller error bars for EDX, it can be concluded that the fluctuations of $\mathrm{Cu}$ concentration are $<10 \%$ of the weight-in concentration (horizontal red line). 

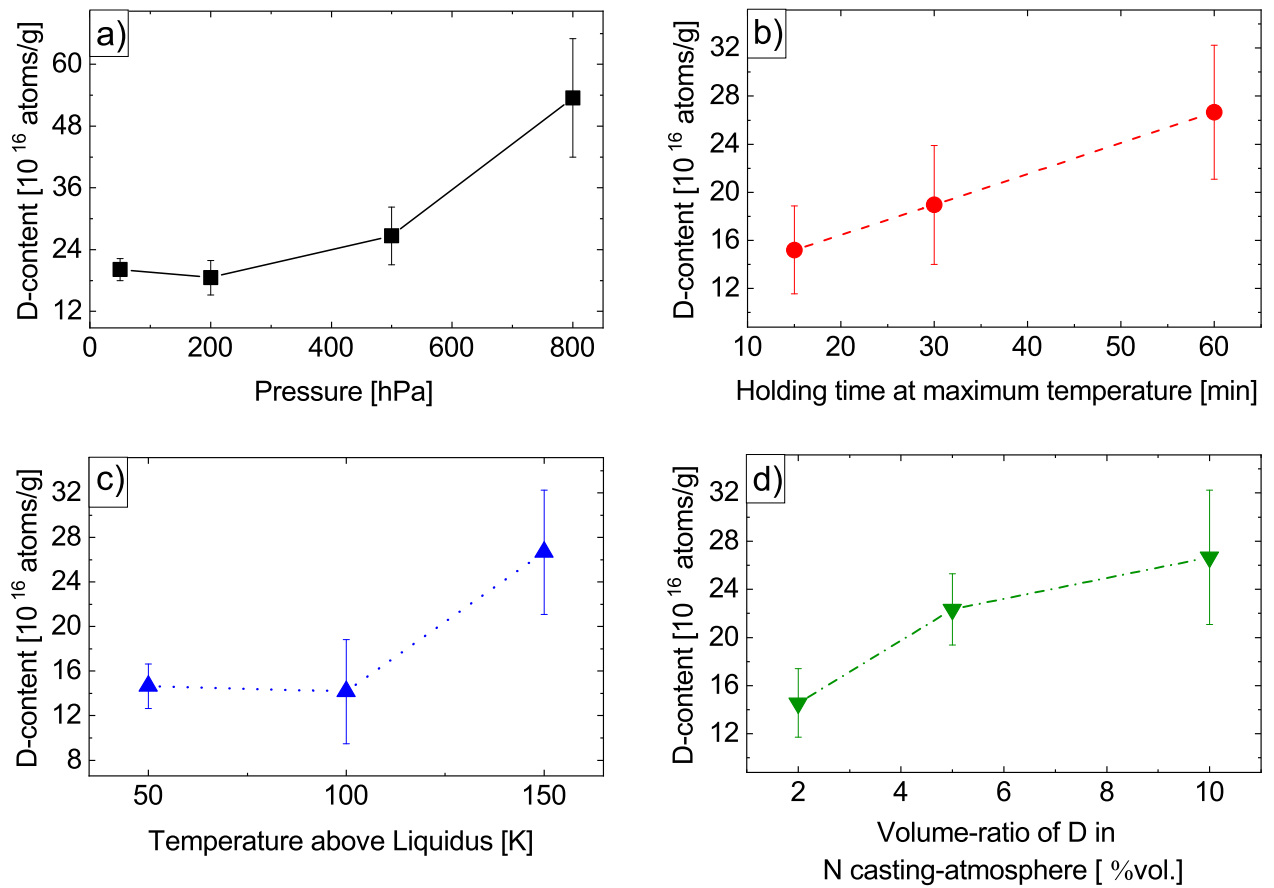

FIG. 4. TDS analysis of the amount of retained $\mathrm{D}$ in the $0.5 \mathrm{~g} \mathrm{Al}-\mathrm{Cu}$ alloy specimen. The Al-10 wt. \% Cu reference sample was cast under $p=500 \mathrm{hPa}, \mathrm{t}=60$ min, $\mathrm{T}=150 \mathrm{~K}$ above liquidus (liquidus temperature $907 \mathrm{~K}$ ), and 10 vol. $\% \mathrm{D}$ conditions. In all other castings, a single parameter was changed. TDS data show an increase in loaded $D$ with the increase in (a) pressure $p$ (black squares), (b) holding time $t$ (red circles), (c) superheating $T$ (blue triangles), and (d) $D$ concentration in the atmosphere (green inverted triangles). cold die, and separate heating inside the casting die for slower cooling rates is not available.

\section{Cu-segregation}

A large difference in melting points between the pure elements used as the raw material results in incomplete dissolution when only short holding times and/or low superheating are applied. This can lead to inhomogeneity of the final casting. Density differences between alloying elements in the melt can have a similar effect on the final product. $\mathrm{Cu}$, with a melting point of $1358 \mathrm{~K}$ and a density of $\rho_{\mathrm{Cu}}=8.94 \mathrm{~g} \mathrm{~cm}^{-3}$, is more than three times denser than $\mathrm{Al}\left(\rho_{\mathrm{Al}}\right.$ $\left.=2.70 \mathrm{~g} \mathrm{~cm}^{-3}\right)$, ${ }^{22}$ and the difference in liquidus temperature amounts to more than $400 \mathrm{~K}$ (melting point $\mathrm{Al}: \mathrm{T}_{\mathrm{m}}=934 \mathrm{~K}$ ). Thus, $\mathrm{Cu}$ segregation toward the bottom of the crucible is a common phenomenon while casting $\mathrm{Al}-\mathrm{Cu}$ alloys. ${ }^{23}$ To compensate for these effects but also to aid the gas-loading process, a stirring mechanism in the form of a grooved carbon rod was added. Temperatures well above the liquidus temperature of pure $\mathrm{Al}$ (reference superheating: $150 \mathrm{~K}$ ) as well as long holding times (reference holding time: $60 \mathrm{~min}$ ) ensured a thorough homogenization of the raw material. As depicted in Fig. 3, EDX and RBS of horizontal slices at distinct heights of the sample show no significant $\mathrm{Cu}$ segregation in neither non-stirred nor stirred samples. It can thus be concluded that the oven allows for homogeneous casting even if the alloy is composed of elements with different densities and melting points.

\section{Casting parameters' effect on gas-loading}

TDS results associate the increasing gas content (within the error bars) with the increasing temperature, pressure, holding time, and $\mathrm{D}$ concentration.

These results (see Fig. 4) correlate with the factors influencing diffusion and saturation, notably temperature, time, and partial pressure. $^{3,24}$ Pressure and D-content appear to be the most crucial parameters, whereas the holding time only shows a significant increase in retained $\mathrm{D}$ for high values $(60 \mathrm{~min})$.

TDS of samples cast under specific parameter combinations confirm the stability of the derived approach, reaching comparable

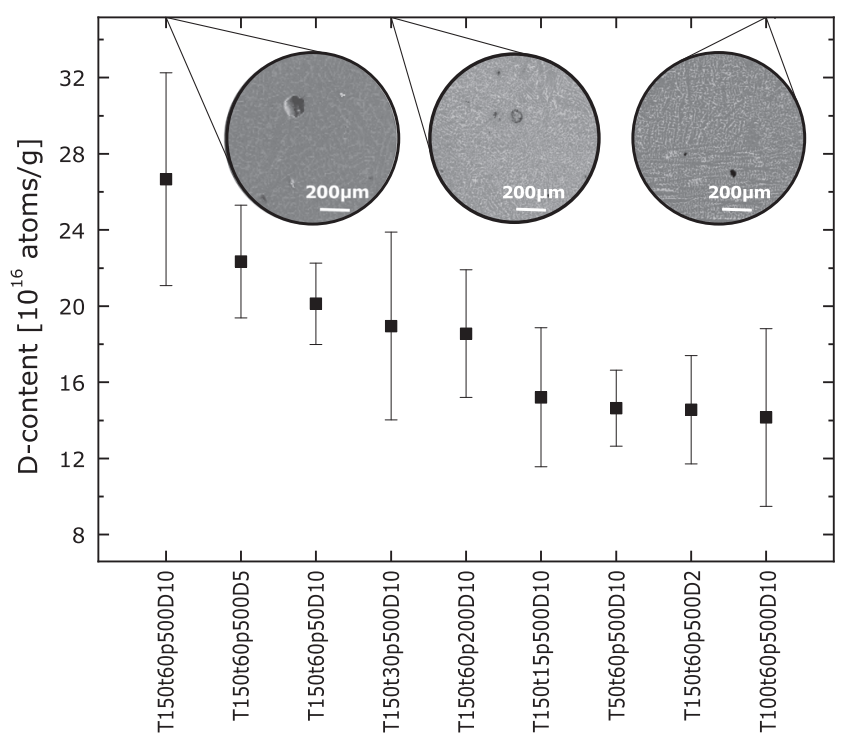

FIG. 5. Demonstration of the ability to reach different levels of $D$ gas-loading through different parameter sets. Concurrent with the decrease in D-content, gas porosity decreases in quantity and size, as can be seen from the SEM images of representative areas of selected $\mathrm{Al}-10 \mathrm{wt} . \%$ samples weighting $0.5 \mathrm{~g}$ each. 

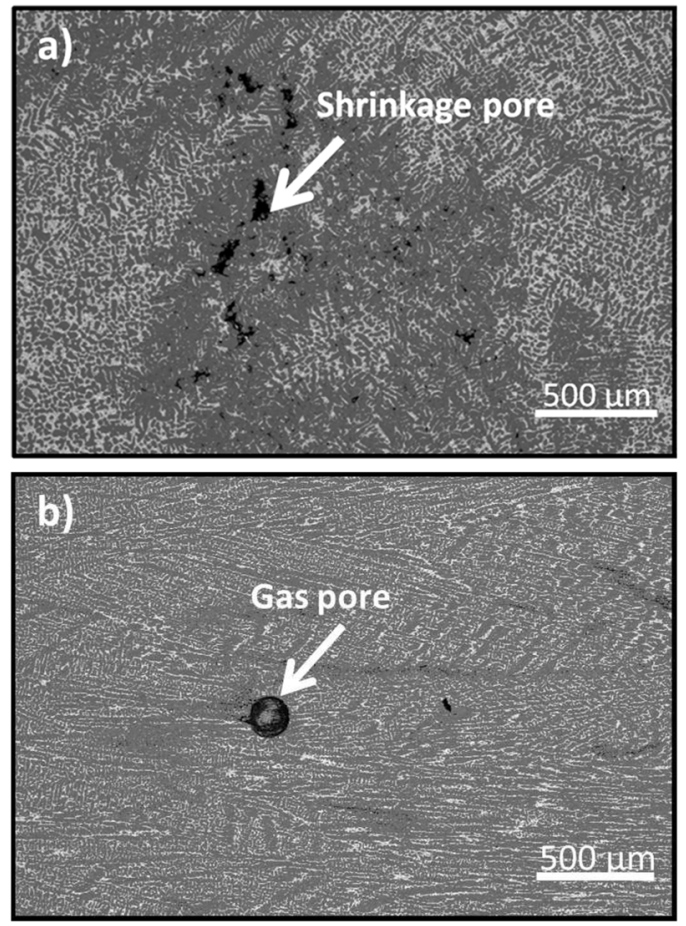

FIG. 6. SEM images using the BSE detector, where Al dendrites are dark gray, while the $\alpha-\theta$-eutectic appears light, of (a) an Al-10 wt. \% Cu sample cast under vacuum, where only shrinkage porosity can be observed, and (b) an $\mathrm{Al}-10 \mathrm{wt} . \%$ Cu sample cast under $10 \mathrm{vol}$. \% D atmosphere at $500 \mathrm{hPa}$, with a holding time of 60 min and a T.a.L. of $150 \mathrm{~K}$, exhibiting gas porosity. The furnace is shown to produce suitable samples for both potential shrinkage and gas porosity experiments.

amounts of gas-loading through different parameter sets, as well as promoting matching levels of gas porosity (see Fig. 5).

\section{Production of gas porosity}

The intended purpose of the furnace is to be able to manufacture samples for either shrinkage or gas porosity experiments. SEM imaging of the obtained specimen confirms that by choosing adequate parameter sets and given a fixed cooling rate of the mold, it is possible to selectively cast samples that only show shrinkage [see Fig. 6(a)] or mainly develop gas pores [see Fig. 6(b)]: By processing the sample in vacuum and thus degassing the specimen, limiting $\mathrm{H}$ gas dissolution, and minimizing the formation of oxide bifilms, the formation of gas pores is circumvented. On the other hand, by adjusting the pressure, holding time, temperature, and D concentration in the casting atmosphere, the amount of trapped D and thus the quantity and size of gas pores in the solidified specimen can be varied.

\section{CONCLUSION}

In the present work, the design and validation of a furnace for $\mathrm{H}$-loading experiments has been presented. Control of the casting parameters proves to be an effective way to adjust the amount of retained gas and, accordingly, the amount of gas porosity. It was shown that different parameter combinations can be used to reach similar $\mathrm{H}$-levels in a sample. Considering the consumption of resources (time and electrical power), as well as taking into account the safety, short high-pressure/high-concentration sessions were found to create the most adequate gas-loading environment for the present purposes. Future studies will discuss in more detail the influence of dissolved and entrapped $\mathrm{H}$ on the formation of gas porosity in solidifying metals, as well as the relationship to shrinkage pores and pore networks.

\section{ACKNOWLEDGMENTS}

The authors thank J. Dorner from the Max Planck Institute for Plasma Physics in Garching for providing help and access to the tandem accelerator for the RBS experiments. Furthermore, we gratefully thank M. Rasiński and A. Houben from the Institute of Energy and Climate Research in Jülich for their help with the TDS experiment, as well as M. J. Püschel for his spot-on linguistic advice. We also gratefully acknowledge C. Dreißigacker's technical support. Finally. we would like to express our gratitude to Professor A. Meyer for the opportunity to conduct the research at his Institute of Materials Physics in Space.

The data that support the findings of this study are available from the corresponding author upon reasonable request.

\section{REFERENCES}

${ }^{1}$ L. H. Shang, F. Paray, J. E. Gruzleski, S. Bergeron, C. Mercadante, and C. A. Loong, "Prediction of microporosity in Al-Si castings in low pressure permanent mould casting using criteria functions," Int. J. Cast Met. Res. 17(4), 193-200 (2004).

${ }^{\mathbf{2}}$ M. Felberbaum, Porosity in Aluminum Alloys: Visualization, Characterization, and Modeling (École Polytechnique Fédérale de Lausanne, 2010).

${ }^{3}$ I. B. Ulanovskiy, Hydrogen Diffusion and Porosity Formation in Aluminium (MISIS National University of Technology and Science, Moscow, 2015).

${ }^{4}$ A. G. Murphy, D. J. Browne, Y. Houltz, and R. H. Mathiesen, "In situ X-ray observations of gas porosity interactions with dendritic microstructures during solidification of Al-based alloys," IOP Conf. Ser.: Mater. Sci. Eng. 117(1), 012067 (2016).

${ }^{5} \mathrm{M}$. Wu, A. Ludwig, and A. Kharicha, "A four phase model for the macrosegregation and shrinkage cavity during solidification of steel ingot," Appl. Math. Modell. 41, 102-120 (2017).

${ }^{6}$ J. P. Anson and J. E. Gruzleski, "The quantitative discrimination between shrinkage and gas microporosity in cast aluminum alloys using spatial data analysis," Mater. Charact. 43(5), 319-335 (1999).

${ }^{7}$ M. Mukherjee, F. García-Moreno, C. Jiménez, A. Rack, and J. Banhart, "Microporosity in aluminium foams," Acta Mater. 131, 156-168 (2017).

${ }^{8}$ J. A. Dantzig and M. Rappaz, Solidification (EPFL Press, Lausanne, 2016).

${ }^{9}$ J. Campbell, Castings, 2nd ed. (Butterworth-Heinemann, Oxford, 2003).

${ }^{10}$ R. M. Hilbinger, S. Gerth, and P. Randelzhofer, "Erzeugung und charakterisierung porenbehafteter prüfkörper für schwingprüfung und gießsimulation," Materialwiss. Werkstofftech. 48(2), 77-87 (2017).

${ }^{11}$ NASA, Safety standards for hydrogen and hydrogen systems. Office of Safety and Mission Assurance, Washington DC 20546, 1997.

${ }^{12}$ J. H. S. Lee, R. Kynstantus, C. M. Guirao, W. A. Benedick, and J. E. Shepherd, "Hydrogen-air detonations," in Proceedings of the 2nd International Workshop on the Impact of Hydrogen on Water Reactor Safety (SAND82-2456), 1982.

${ }^{13}$ J. H. S. Lee, "Initiation of gaseous detonation," Annu. Rev. Phys. Chem. 28, 75104 (1977).

${ }^{14}$ M. M. Avedesian and H. Baker, Magnesium and Magnesium Alloys (ASM International, Almere, 1999).

${ }^{15}$ ASTM, E3-11: Standard Guide for Preparation of Metallographic Specimens (ASTM International, West Conshohocken, PA, 2017). 
${ }^{16}$ J. I. Goldstein, D. E. Newbury, D. C. Joy, C. E. Lyman, P. Echlin, E. Lifshin, L. C. Sawyer, and J. R. Michael, Scanning Electron Microscopy and X-Ray Microanalysis, 3rd ed. (Kluwer, New York, 2003).

${ }^{17}$ ASTM, E1508-12a: Standard Guide for Quantitative Analysis by EnergyDispersive Spectroscopy (ASTM International, West Conshohocken, PA, 2012).

${ }^{18}$ INCA, Operator Manual Issue 2.1 (INCA Energy, 2006).

${ }^{19}$ M. Mayer, SIMNRA User's Guide, Report 9/113, Max-Planck-Institut für Plasmaphysik, Garching, 1997.

${ }^{20} \mathrm{~J}$. R. Tesmer and M. Nastasi, Handbook of Modern Ion Beam Materials Analysis (Material Research Society, Pittsburgh, PA, 1995).
${ }^{21} \mathrm{~K}$. Verbeken, "Analysing hydrogen in metals: Bulk thermal desorption spectroscopy (TDS) methods," Gaseous Hydrogen Embrittlement Mater. Energy Technol. 1, 27-55 (2012).

${ }^{22}$ L. Selwyn, "How to determine metal density," Canadian Conservation Institute (CCI) Notes 9/10, 2016

${ }^{23}$ F. Bertelli, C. Brito, I. L. Ferreira, G. Reinhart, H. Nguyen-Thi, N. MangelinckNoël, N. Cheung, and A. Garcia, "Cooling thermal parameters, microstructure, segregation and hardness in directionally solidified $\mathrm{Al}-\mathrm{Sn}-(\mathrm{Si} ; \mathrm{Cu})$ alloys," Mater. Des. 72, 31-42 (2015)

${ }^{24}$ E. L. Cussler, Diffusion, Mass Transfer in Fluid Systems (Cambridge University Press, New York, 2009). 